Fall 2015

\title{
Funding the Costs of Disease Outbreaks Caused by Non Vaccination
}

Robert L. Schwartz

University of New Mexico - School of Law

Follow this and additional works at: https://digitalrepository.unm.edu/law_facultyscholarship

Part of the Health Law and Policy Commons

\section{Recommended Citation}

Robert L. Schwartz, Funding the Costs of Disease Outbreaks Caused by Non Vaccination, 43 Journal of Law, Medicine and Ethics 633 (2015).

Available at: https://digitalrepository.unm.edu/law_facultyscholarship/646

This Article is brought to you for free and open access by the UNM School of Law at UNM Digital Repository. It has been accepted for inclusion in Faculty Scholarship by an authorized administrator of UNM Digital Repository. For more information, please contact amywinter@unm.edu, Isloane@salud.unm.edu,sarahrk@unm.edu.

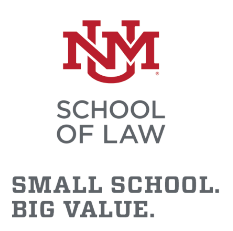

BIG VALUE. 


\title{
Funding the Costs of Disease Outbreaks Caused by Non Vaccination
}

\author{
Charlotte A. Moser, Dorit Reiss, Robert L. Schwartz
}

\section{Introduction}

Preventable diseases not only cause suffering and physical harm, they also impose financial costs on private individuals and public authorities. By disregarding evidence of the safety and effectiveness of vaccines and choosing not to vaccinate their children some parents are increasing the risk of outbreaks and their attendant costs. Since nonvaccinating can directly lead to costly outbreaks, this paper argues that it is both fair and desirable to impose those costs upon those making the choice not to vaccinate. There are, in fact, strong policy reasons to support doing so regardless of whether we use an approach-based-fault or a no-fault framework. Not only can the decision not to vaccinate be seen as culpable, aside from the culpability consideration it is appropriate to compel those deciding not to vaccinate to internalize the costs in order to prevent free riding and to mitigate harms to others.

This article addresses the legal tools that can be used to manage the costs associated with outbreaks, focusing on those that do not require demonstrating fault. In particular, the article considers the imposition of a fee or a tax on non-vaccinators so that those who avoid immunization are required to internalize the costs associated with their decisions.

\section{Costs Associated with Non-Vaccination}

Widespread use of vaccines has transformed the landscape of medicine. Diseases that were once significant causes of morbidity and mortality are, in some cases, no longer 
suspected when patients report with symptoms characteristic of these diseases (Chen, 2011; Sugerman, 2010; Calugar, 2006; Lee, 2000). In fact, according to a recent study by William van Panhuis and colleagues (van Panhuis, 2013), vaccines have prevented about 103 million cases of disease since 1924. Despite the unquestionable effectiveness and proven safety of vaccines, some parents are concerned enough about the safety of vaccines that they choose not to have their children vaccinated (Salmon, 2005). While the number of completely unvaccinated children remains low, pockets of unimmunized individuals make some communities particularly susceptible to outbreaks (Omer, 2006; Omer, 2008). In recent years, outbreaks of the most contagious diseases, such as measles and pertussis, have started to reappear in communities throughout the country (MMWR, 2008; Ortega-Sanchez, 2014; MMWR, 2012). Recent examples include outbreaks of measles in New York, California, Washington, and Ohio; and one of mumps in Ohio. A recent press announcements by the CDC stated that the number of measles cases in the United States in the first half of 2014 was the highest since 1994.

Outbreaks are more likely to occur where pockets of susceptible people cause a breakdown in herd immunity. Herd immunity results when enough individuals are immunized, so that the few who are not are still afforded protection. In fact, data have shown that it is better to be an unimmunized person in a highly vaccinated community than to be an immunized person in a community of susceptible people (Feikin, 2000; von den Hof, 2002). because the disease will be less likely to penetrate a highly vaccinated community, so it is less likely that an unimmunized person will be infected. In contrast, an infectious agent will spread more readily through a lesser vaccinated population resulting in infections in both unimmunized individuals as well as those for whom the 
vaccine was not effective. When families choose not to immunize themselves or their children, discussions often focus on the health consequences that the breakdown in herd immunity imposes on individuals and society. However, society must also absorb some of the financial burden related to cases of infectious diseases.

When an individual contracts a preventable disease, the costs are typically covered by the individual or family, their insurance company or, if they lack private insurance, a federally funded program, such as Medicare or Medicaid. Individual costs are incurred for medications (over-the-counter or prescription), co-pays and uncovered procedures or treatments, and loss of productivity (time at doctor visits or not at work). Several variables affect these costs, including who in the family is ill, which disease they have, the severity of illness, and the extent of their private or public medical coverage. Lee and Pichichero studied costs to families during a pertussis outbreak in New York during 1995-96 and found costs to families were $\$ 181$ per ill adult, $\$ 254$ per ill adolescent, $\$ 308$ per ill child, or $\$ 2,822$ per ill infant (Lee, 2000). In 2014 US dollars, these costs would range from $\$ 278$ - $\$ 4,331$. While these costs could seem exorbitant to individual families, they are minor when compared with the lifetime medical costs for an individual who is permanently harmed as well as the costs associated with stopping the spread of an infectious disease. Both of which are significantly higher and ultimately absorbed by society.

\section{Costs associated with permanent harm}

While most infectious diseases can lead to permanent harm, rubella and meningococcal disease may be among the worst. For example, a pregnant woman 
infected with rubella may miscarry, deliver early, suffer a spontaneous abortion or stillbirth, or have a child born with congenital rubella syndrome (CRS). Children affected by CRS can suffer deafness, heart or eye damage, mental retardation, skeletal damage, autism, or some combination of these. If the child survives, the cost to care for the child over his or her lifetime is estimated to be about \$143,000 (2014 US dollars; Babigumira, 2013). Likewise, about 10-20 percent of the people who survive meningococcal infection, which can cause bloodstream infection (sepsis) or meningitis, will have permanent consequences such as deafness, limb amputations, or neurologic disabilities. Costs associated with acute disease and lifetime medical costs for these individuals have been estimated to range from $\$ 87,261$ for deafness to $\$ 253,723$ for someone with multiple amputations (2014 US dollars; Shepard, 2005). Most of the costs associated with permanent harm caused by an infectious disease are absorbed by the family and its insurer. Because private insurers base their fee structures on calculated risks, costs associated with permanent harm are passed on to participants through premiums. For those insured through public programs, such as Medicare or Medicaid, costs associated with permanent harm are absorbed by tax payers.

\section{Costs associated with containment measures}

When an infectious disease is identified, one of the most pressing concerns becomes stopping the spread to others. Containment measures include limiting exposure of infected individuals to others who may be susceptible; identifying those who were exposed; monitoring for additional cases; establishing diagnostic testing and preventive or treatment measures, such as vaccine clinics; alerting and updating healthcare providers 
and the Centers for Disease Control and Prevention (CDC); and addressing the public and the media (Ortega-Sanchez, 2014). A measles outbreak in 2005 showcases the complexities (Parker, 2006):

When an unvaccinated six year old was hospitalized with measles in Illinois, public health officials in that state traced the child's exposure to a church gathering of 500 people two weeks prior - in Indiana. When the Indiana health department began investigating, they identified the source case as an unvaccinated teenager who had returned from a church-mission trip. Despite symptoms of illness, she attended the church gathering where she not only directly infected the hospitalized child, but also seventeen others attending the gathering and one other person during a visit with a neighbor (19 first generation infections). In addition, thirteen additional people were infected by close (household) contact with the 19 directly infected individuals (second generation infections). Public health officials attempted to contact the 500 picnic attendees as well as anyone in contact with what ultimately became 34 people infected over three generations of spread. Workers had to ascertain vaccination status of attendees, attempt to identify additional cases, and try to get unvaccinated individuals vaccinated. Containment activities involved "ninety-nine public health officers and infectioncontrol personnel working in 12 health departments and health care facilities. . . .’(p.449). These personnel reported 3,650 hours of work, 4,800 telephone calls, 5,500 miles driven, and 550 lab samples to contain the outbreak started by a single unvaccinated teen returning from travel.

The cost of containment for public health authorities was $\$ 62,216$. The total cost of the outbreak was over two hundred thousand dollars (see Table 1). 
While the aforementioned outbreak started at a church gathering, outbreaks can begin anywhere that people gather. For example, in 2000, a measles-infected traveler exposed 335 passengers on a plane (Lasher, 2004). Although passengers were alerted of the potential exposure on the plane, public health officials decided to follow-up with additional information the next day leading them to track down passengers at hotels, in tour groups and by telephone. In this case 97 percent of the passengers were residents of Japan, two percent were U.S. citizens and 1 percent was from Indonesia.

Likewise, a measles outbreak in Pennsylvania in 2007 was associated with an international youth sporting event (Chen, 2010). The index case was an international participant in the sporting event who was ill during travel. Because he was staying in a residential compound associated with the event, eight U.S. teams and eight international teams as well as their coaches and event staff were potentially exposed. Likewise, people on the child's two flights were exposed as were nine corporate representatives working the event. One of these nine representatives got measles, but not before traveling to Texas and visiting three college campuses before being diagnosed. Two college students were infected by this corporate representative. In total, seven cases occurred (including the index case) and 1,250 people were potentially exposed in California, Georgia, Illinois, Indiana, Maryland, Michigan, Pennsylvania and Texas.

Because each situation is different, the extent of and need for containment measures varies. In addition, the responsibility for and distribution of the financial burden $\theta f$ associated with containment may also vary. For example, in 2008 a measles-infected traveler visited a hospital resulting in an additional 13 cases, most of which were acquired by others in the hospital at that time or secondary cases related to those people. 
Costs to that hospital were estimated to be around $\$ 632,084$ (\$695,993 in 2014 US); most of which was related to wages and salaries of furloughed workers (Chen, 2011). In contrast, when a refugee entered the US while infected with measles in 2010, containment measures were spearheaded by the state public health department, but also involved personnel from the local public health and refugee departments, CDC, and hospital personnel. While the containment succeeded in stopping the spread of measles to others, the $\$ 25,000$ ( $\$ 26,818$ in 2014 US dollars) costs associated with this single case fell completely to the government (Coleman, 2012).

\section{Paying the costs associated with infectious diseases}

While the government supports public health, the annual budget does not typically garner large percentages of the whole. For example, of the $\$ 973.6$ billion in the FY14 federal budget, only $\$ 4.6$ was earmarked for public health (US Government Spending, 2014), and a recent report by Trust for America's Health called for increases in core funding at all levels of public health after presenting data showing that variability in health statistics between states was related to variation in funding (Trust, 2013). In addition, public health departments are not funded for unexpected events, which means that during an outbreak caused by an infectious disease, departments may need to reassign staff and reallocate funds to complete containment measures in a timely manner (Ortega-Sanchez, 2014). A 1995 outbreak in Minnesota is instructive (Osterholm, 2001):

Nine cases of invasive meningococcal disease with one death and seven cases of streptococcal disease with four deaths occurred over a one month period during the winter of 1995 in Minnesota. The cases occurred in two towns and were coincident with influenza season 
thereby complicating diagnoses in those presenting with respiratory symptoms. Containment measures included immunizing 30,000 residents; 26,000 of whom were vaccinated over a 4-day period. Public health staff worked 18-hour days for more than 23 days; in all, more than 600 people were involved in the public health response. Costs of vaccine alone were $\$ 1.2$ million (\$1.8 million 2014 US dollars). The state health department's budget for that year was \$2.2 million (\$3.4 million 2014 US dollars). While the state legislature provided an emergency appropriation for vaccine costs, the local hospital, which had to set up a separate emergency area, was never reimbursed.

Table 1 summarizes studies of costs associated with investigating and containing recent cases and outbreaks of infectious diseases throughout the US.

\section{Costs and Savings Associated with Vaccination}

Recently, researchers at the CDC compared the costs of the vaccination program with the costs savings over the lifetime of a single birth cohort (Zhou, 2014). Using the 2009 US recommended immunization schedule and a hypothetical U.S. birth cohort of more than 4.2 million children, the researchers calculated estimated cases of disease and deaths as well as the direct and societal costs associated with the diseases, immunizations, and net differences. Direct costs included inpatient and outpatient visits as well as outbreak control; indirect costs included loss of productivity and premature death. In addition to preventing about 42,000 deaths and 20 million cases of disease, vaccines were estimated to save about $\$ 14.7$ billion (2014 US dollars) in direct costs and $\$ 75$ billion (2014 US dollars) in societal costs over the lifetime of the cohort. 


\section{Costs of Outbreaks in the Eyes of the Law}

The costs associated with outbreaks are unquestionably substantial and many constitute legally compensable damages. For example, direct costs of a tortious act are compensable and, in a case concerning a preventable infectious disease, may include the costs of treating current cases and preventing further ones. In addition, when an individual has been afflicted with an infectious disease their costs may include lost earnings, future lost earnings (losing the ability to work generally or to work in specific types of jobs), physical and emotional pain and suffering (as allowed by the particular state), and subsequent decrease in life expectancy. Additional relevant costs are costs associated with inability to perform household tasks. If the afflicted individual dies as a result of the disease, relatives of the individual can sue for wrongful death, and for the harm they suffered as a result of the loss, including economic contributions that individual would have made, lost value of services, and loss of companionship. Individuals may also recover for pain and suffering, including physical pain and emotional harm accompanying a physical injury or illness (though some states limit pain and suffering awards in some or all contexts). In some rare cases, where behavior is especially culpable, for example, intentionally exposing a child to chickenpox, punitive damages may also be appropriate.

\section{The Justification for Recouping Costs}

Whether it is appropriate to compel an individual to bear the costs associated with the decision to not vaccinate is an important starting point to this discussion. It is especially important in terms of those costs generally imposed on the public purse and 
financed through taxation for the benefit of all. Sometimes, society does pay for problematic choices made by individuals. For example, individuals are generally not required to pay for police activity caused because they got into a dangerous situation. This is not always the case, however. For example, when individuals tortuously cause damages to public property, they are responsible for the damages even though the property has been purchased and maintained with public funds (Pennsylvania v. Gen. Pub. Utils. Corp., 710 F.2d 117, 122-23 (3d Cir. 1983)).

Whether we use a fault or a no fault basis, there are powerful public policy reasons to compel those choosing not to vaccinate to bear the costs associated with their actions (Caplan, 2012 \#4148).

\section{A Fault-Based Argument for Recouping Costs}

Not vaccinating is, arguably, at least negligent. As mentioned above, the risks of vaccinating are substantially smaller than the risks of not vaccinating (Calandrillo, 2004) As a result, vaccination is supported by the overwhelming majority of doctors, scientists and policy makers. Both from a risk/benefit analysis and through a community norm lens, the failure to vaccinate is problematic. The justifications for not vaccinating are often based on information that is simply incorrect (Kennedy, Brown et al. 2005). In truth, modern anti-vaccine arguments are surprisingly similar to those used in the early days of vaccines, and are no better supported by evidence today than they were in the $19^{\text {th }}$ century or the early $20^{\text {th }}$ (Offit 2010).

Unlike intentional torts, negligence does not require actual knowledge that one's understanding of the risks is wrong or that one is making a risky choice. As long as the 
decision maker should have known that the decision was unreasonable, then the decision is negligent. Given the scientific consensus supporting vaccines, the abundant information from reputable sources supporting immunization, and the problematic sources relied upon by those who choose not to vaccinate, it is easy to support the claim that those who choose not to vaccinate should know they are making an unreasonable choice. As is the case here, when an individual engages in behavior that free rides on others, puts others at risks, and is unreasonable or even reckless, there is strong justification to require the individual to internalize the costs of that behavior.

\section{A No Fault-Based Argument for Recouping Costs}

An argument can be made that the choice not to vaccinate is not always negligent. In reality, the reason for failing to vaccinate children is rarely the result of parents forgetting to bring children to the pediatrician or the pediatrician's failure to remember to provide the vaccination. Rather, failure to vaccinate is occasionally the result of intentional actions based on serious religious or philosophical principles or is the result of safety concerns. In most cases, we do not categorize principle-based decisions as "negligent," even when most of the society rejects the same principles. For example, the law does not characterize a woman's decision to carry a pregnancy to term and not to have an abortion following a negligently performed tubal ligation as a negligent failure to mitigate damages. Because there is sufficiently widespread support for an individual woman's right to choose to have a baby or choose to have an abortion, no court has ever declared that choosing one option over the other is negligent. Similarly, Jehovah's Witnesses generally are not found to be negligent for refusing medically necessary blood 
transfusions on religious grounds, even though the vast majority of the society rejects their religiously based principle. ${ }^{1}$ Whether we are willing to declare a parent to be negligent for failing to vaccinate a child may be a harder question, but it involves the same considerations, especially when it is done for religious reasons. A case can be made based in part on the reasoning in Prince v. Massachusetts, that parents cannot use their religious principles to endanger a child's health (Prince v. Massachusetts, 321 U.S. 158, 166-67 (1944)). In fact, some jurisdictions have applied a recklessness standard and convicted parents for manslaughter when the reasons underlying decisions that led to a child's death were religious (Commonwealth v. Twitchell, 617 N.E.2d 609 (Mass. 1993); State v. Norman, 808 P.2d 1159 (Wash. App. 1991)). This conclusion is not, however, obvious, nor is it consistent with the prevailing view of negligence in the tort context.

The second alternative, deciding not to vaccinate based upon ill-founded safety concerns, is more obviously akin to negligence. Acting according to your best judgment but choosing a larger risk can be negligent (Vaughan v. Menlove, 132 Eng. Rep. 490 (C.P.) (1837) (“[W]hether the Defendant had acted honestly and bona fide to the best of his own judgment ... . would leave so vague a line as to afford no rule at all ... . [Because the judgments of individuals are ... ] as variable as the length of the foot of each ... we ought rather to adhere to the rule which requires in all cases a regard to caution such as a man of ordinary prudence would observe")). Sincere belief that your choice is the correct one does not make it any less negligent when it imposes risks on others.-Even in those cases, however, a court may find for the defendant on the basis that an error of judgment

\footnotetext{
${ }^{1}$ One court has been willing to reduce damages for a plaintiff who agree to forgo blood transfusions and subsequently suffered greater injury because she could be provided blood, but that was justified by some version of the doctrine of assumption of the risk rather than contributory or comparative negligence (Shorter v. Drury, 695 P.2d 116 (1985), cert. denied Shorter v. Drury, 474 U.S. 827 (1985)).
} 
is not always negligent (Reed v. Tacoma Ry. \& Power Comp., 188 P. 409 (Wash. 1921)).

Given the abundance of anti-vaccine misinformation on the Internet (Wolfe, 2005) some judges or juries may find that the decision not to vaccinate was an error on judgment, rather than a negligent act.

However, even if the decision to forego vaccination is not regarded as negligent, imposing the cost on the decision maker is justified for a number of reasons. The most important reason is that the question of childhood vaccination imposes unusual pressures upon parents which can be analogized to the prisoner's dilemma, whereby it is in the interest of each individual to make a decision that will undermine the social interest of all of the decision makers. Assuming that there is substantial value in herd immunity and that there are some adverse side effects of immunization that cannot be controlled, each individual child would be better off if that child were not vaccinated (so she would avoid any risk of side effects) and every other child were vaccinated (giving the one unvaccinated child the protection of herd immunity). In other words, there are some circumstances where virtually everyone else in the community is vaccinated - in which parents would be acting rationally in deciding not to vaccinate their children, as long as their only consideration is the health of that child. In these cases, people would rely intentionally or not - on others to protect them or their children against diseases rather than take the small risk vaccines pose. In other words, they would be free riding on herd immunity (Fine, 2011).

This situation can also be analogized to the tragedy of the commons, where a common good is put at risk by individuals acting in their own self-interest. Here the commons - the disease free state of an immunized community - is put at risk by people 
who depend upon that commons for their own benefit. While people sought to opt out of vaccination from the earliest days of immunization for the same reasons that are now advanced, this problem was not so severe when parents often saw children who were harmed by the diseases we vaccinate against and understood the risks facing their own children. Today, few parents have ever seen these conditions and, as a result, most do not fully understand the potentially terrible consequences of these preventable diseases. On the other hand, stories of vaccine injuries, most of which, like the claim that vaccines cause autism, are not based on credible medical evidence are advanced by anti-vaccine movements; and may easily scare parents.

Regardless of whether a parent's decision to forego vaccination is made as a conscious decision to "hide in the herd," or is based upon an incorrect belief that their children are not really at risk from preventable diseases or that the risks of vaccines are greater than those of the diseases, in all of these cases the parents' decisions not to immunize threaten both the social consensus on vaccination and the herd immunity on which they rely. We can justify imposing costs upon these parents both as a deterrence mechanism, which may force them to consider the costs associated with their decisions, and as a matter of fairness, to prevent them from forcing others to pay for the risks created by their decisions.

From a public policy perspective, not vaccinating imposes avoidable costs on government which lead to decreased funding for other important public health programs. Not vaccinating also increases the risk of outbreak to the community by undermining herd immunity. Imposing costs upon those who choose not to vaccinate can help deter 
individuals from making such problematic choices without limiting their autonomy with a vaccination mandate.

One possible claim is that by allowing school immunization requirements, the legislature had provided a right not to vaccinate and therefore imposing costs is inappropriate. Even if our proposal was focused on common law suits, we believe that claim unjustified: exemptions from school immunization requirements balance public health with parental rights in the context of the child's education, considering the importance of education for children. There is no indication that in passing them the legislature considered the question of the cost of harms from non-vaccination. Further, acting legally is not always acting reasonably, and costs are imposed, under our system, for acts that are legal but not reasonable when those acts harm others (Reiss, 2014). But since our remedy is a statutory one, this is not a problem: in the same way that the legislature can choose to provide or not provide an exemption, the legislature may impose costs on those using exemptions.

\section{Legal Tools for Imposing Costs}

There are four general types of mechanisms for imposing costs. While this article briefly mentions all of them, only the fourth will be explored in detail. The first and most coercive mechanism, is the use of criminal law. For example, in Jacobson v. Massachusetts, the United States Supreme Court recognized that a state can impose a fine for failure to obtain an immunization against a communicable disease that the state reasonably believes is threatening the community (Jacobson v. Massachusetts, 197 U.S. 11, 25-27 (1905)). The criminal approach assumes that those who do not receive 
vaccinations have an even higher level of culpability than negligence- Because the possibility of imposing costs through criminal law liability is a subject that deserves its own treatment, it is not explored in this article.

The second mechanism is the use of the coercive power of the law to condition social activities on vaccination without formally invoking criminal law. Today we enforce mandatory vaccination policies primarily through attendance at school (or, in some states, only public school). It makes a great deal of sense to use school attendance as the conditioning factor because of the importance of immunizing children and the potential for contagion at schools. On the other hand, there are additional activities that could be dependent upon vaccination, too. For example, the use of public meeting places likes parks, pools and water parks, government buildings, theaters, sporting venues, shopping centers, and other public accommodations could each be conditioned on the vaccination of the people using it although, admittedly, enforcing these restrictions could prove challenging and people may resist the requirement to carry evidence of their vaccination status whenever they are in public. Like mandatory vaccination for school attendance policies, these other vaccination requirements could allow for vaccination optouts or could be enforced only when particular legally identified circumstances occur. For example, they could be enforced only when there is an outbreak of a disease or the vaccination level in the community falls below herd immunity levels.

The third mechanism is to allow suits in negligence for non-vaccination. This possibility, and its challenges, have been discussed elsewhere (Caplan, 2012; Reiss, 2014). However, bringing a negligence case is not easy; even meritorious cases may be difficult for plaintiffs to win because there may be substantial problems in proving 
causation, and because they will need to overcome the duty hurdle. In addition, on a social level, negligence actions are a highly inefficient way to resolve disputes, in large part because the cost of enforcing an obligation through the use of negligence law is very high. So while this approach provides an option, it is likely that other more effective and efficient legal devices are available to encourage vaccination and properly distribute the cost of the failure to vaccinate.

The fourth alternative mechanism for imposing costs, and the one this article examines in depth, is a no-fault approach that seeks to force every person who opts out to internalize the cost of the failure to vaccinate so that the one who incurs the cost is the one who bears it. The no-fault approach would cause those who decide against vaccination to internalize the cost of that decision by imposing a tax, fee, premium or other cost equal to the actuarially based cost of avoiding the immunization. Like the Arizona Stupid Motorist Act, or similar statutes allowing for the collection of rescue costs for lost hikers and skiers, or like the federal Superfund administered by the EPA, which is based on ordinary principles of negligence, the justifications for putting such a scheme in place to impose costs associated with the failure to vaccinate may draw on the culpability of the action. Alternatively, efforts to impose costs may be more like governments' attempts to collect the direct costs of their services like city trash collection fees (where the fees collected must actually cover the costs of trash collection) or bridge tolls (where the toll is priced to cover bond payments on the bridge and operating expenses). Cost imposition may have some of the attributes of congestion pricing, like the costs being imposed on drivers of cars that enter central London or demand-based parking pricing in San Francisco, where the price goes up as the number of users (in our 
case, non-vaccinators) goes up, increasing the cost to society. Imposition of costs could also be analogous to the "headless motorcycle rider" statutes being suggested in some states where the fee to register a motorcycle that could be driven by someone without a helmet would reflect the additional costs to society of that risk (estimated to be between $\$ 600$ and $\$ 1000$ each year above the regular registration fee). While some of the costs of these actions are already internalized (after all, non-vaccinators' children may acquire these diseases) without an effective legal intervention, many of the costs associated with communicable diseases are imposed on vaccinated members of society or those who cannot be vaccinated.

The mechanisms discussed here all probably require a legislative change.

\section{No-Fault Tools for Covering the Costs Associated with Non-Vaccinating Ex Ante Tools: Taxes, Fees or Costs}

One way to manage the problem of the costs of non-vaccinating is to impose the costs of the choice not to vaccinate upfront, ex-ante (before the fact). In other words, we can make those who do not vaccinate pay a certain sum to the public purse or insurance companies to cover costs imposed by the outbreak they cause before an outbreak ever happens. This approach has the advantage of supplying the money in advance, of distributing the costs of the risk they create among the entire non-vaccinating population, and of absolving the government from showing causation. It can, however, run into implementation problems, including the difficulty of assessing an appropriate amount, of identifying non-vaccinating parents and collecting the money. It also imposes costs on those who may never actually cause an outbreak. In a sense, this approach makes the non-vaccinating pay for the risk they create, not for costs they impose. 
There are many ways in which such fees, taxes or costs could be assessed and imposed. As noted earlier, currently the most common mechanism for assuring childhood immunization in the United States is the requirement that parents provide proof of vaccination at the time of their children's school registration. Current law in all states allows parents to opt out of vaccination for their children when it is medically prudent to do so, and the law in all but two states permits parents to opt out for other reasons, including religious, philosophical or personal objections. Thus, the least disruptive way to have parents internalize the cost of failing to vaccinate their children may be to impose an opt out fee equal to the actual cost to all of society of having another child unvaccinated. This fee might vary by locality, by incidence of disease, or by the number of others who have opted out. As the number of whooping cough cases increases, for example, the opt out fee could increase; as the number of people opting out of whooping cough immunization increases, the opt out fee could increase. The need for flexibility and the fact that fees will vary according to circumstances, suggests that the fee should be determined by an administrative agency rather than by legislation, potentially in a manner similar to the assessment of utilities rates. For example, states use Public Utility Commissions to periodically determine energy rates. While rate setting is complex, states are accustomed to grappling with this challenge and could apply their experience to nonvaccination as well. Furthermore, using commissioners appointed for fixed, lengthy terms, ideally with expertise in related fields, can help isolate the process from political pressures.

While Jacobson held that the right to opt out for medical reasons was Constitutionally protected by the due process clause, all other opt outs could be assessed 
a consistent fee because, regardless of their different underlying reasons, these decisions impose the same cost on society. When transferring these costs to those who decide not to vaccinate, the state would be making a purely economic determination devoid of moral judgment and without evaluation of the sincerity or honesty of the parents. In fact, the statute creating the scheme would determine which opt out factors may be considered.

Of course, an opt out fee is not the only way that parents could be effectively required to internalize the costs they impose on others by failing to vaccinate their children. The cost could be assessed as a tax payable along with income or other taxes to the federal government or the state, or those who do vaccinate themselves and their children could be given tax credits (Parkins, 2012). Alternatively, cash grants or benefits could be provided to families in which everyone is vaccinated. Politically, it is easier to allow for tax credits and deductions than to impose penalties, although behavioral research suggests that the incentive value of a penalty is greater than the incentive value of a credit or deduction, even when the formal economic value of each is the same.

The actuarial work required to determine the appropriate cost of an opt-out and the collection of any such fees could be effectively delegated to private instead of a public agencies, as well. For example, one of the primary costs of failure to vaccinate is the medical cost incurred by the unvaccinated person. Currently, the ACA allows for health coverage premiums to be rated on only four grounds: (1) age, (2) geography, (3) smoking status, and, sometimes, (4) participation in wellness programs. Vaccination status could be an additional rating factor used in policies recognized under the ACA (and, presumably, other policies as well). In fact, the decision to have a vaccination, like 
the decision to have a blood pressure measurement done, could be considered evidence of participation in a wellness program. Anyone can participate in a vaccination program, and anyone can succeed without reference to their health status; thus, a program offering vaccinations to those who for whom they are medically appropriate would seem to meet the requirements for ACA recognized wellness programs. Those who do not get recommended immunizations without a medically valid reason, though, would be subject to higher monthly insurance premiums and would be forced to internalize at least a part of the costs of the failure to vaccinate (Lobel and Amir, 2011).

\section{The Public Use of Revenue Raised from Taxes and Fees Imposed on Non- Vaccination}

A tax or fee might be used to raise general revenue for the government, but a tax on failure to vaccinate may be seen as harsh and unfair to those who have made religiously or philosophically driven decisions to avoid vaccination. There may be far greater public support for a tax or fee that is designated for particular purposes related to the failure to vaccinate. For example, the revenue can be used to pay the cost of vaccinations, the cost of tracing the source of communicable diseases, the cost of caring for those who are injured by the failure to vaccinate, the cost of public and professional education about immunization, and the pain and suffering of those who could not protect themselves against the underlying diseases. If a state decides to use a no-fault mechanism to impose the cost of non-vaccination on those who should bear it, it would make political and economic sense to direct the resources to a fund to be used for that purpose.

Every tax, fee or other incentive with regard to immunization will have to be consistent with the Constitutional limitations of the due process clauses of the Fifth and 
Fourteenth Amendments, and with the religion clauses of the First Amendment. Since the United States Supreme Court approved the imposition of criminal penalties against those who refused locally mandated vaccinations for other than medical reasons a century ago, it is hard to question the general validity of such laws. Indeed, if criminal penalties intended to compel compliance are justifiable, then the imposition of other fees and taxes that are related to the actual cost of noncompliance seem likely to be Constitutionally sound.

Since the Supreme Court upheld the state use of mandatory school attendance law to enforce vaccination laws in Zucht v. King, it has been clear that a state can enforce its immunization requirements through school registration requirements (Zucht v. King, 260 U.S. 174 (1922)). Because Jacobson was decided before the First Amendment was applied against states, there may still be a free exercise clause argument against requiring vaccinations that are contrary to religious principles. On the other hand, limitations put on free exercise claims to exemptions from generally applicable laws in the Smith case (1991) strongly suggest that such arguments will not be successful, at least under current law. The United States Constitution is unlikely to hinder any state action imposing a tax, fee, penalty, or any other cost on someone who does not arrange for vaccinations required by law without having a medical excuse.

\section{Ex Post: Billing by Public Health Authorities}

An alternative to an ex-ante approach is to allow the public health authority to recoup their costs after the fact by sending a bill to a family whose decision not to vaccinate caused the outbreak. This approach has the advantage of adhering to traditional 
principles of causation, and prevents the problem of determining and implementing a fee or tax structure by connecting the amount collected to the harm caused. It has the disadvantages of requiring proof of causation - not always easy - and of placing the entire cost on one family or a few families rather than distributing it across all nonvaccinating individuals, making that family bear the costs associated with a choice made by many, regardless of their ability to bear the cost.

While this approach draws on tort principles of individual responsibility and causation, it creates a public law remedy.

Under the Free Public Services Doctrine, municipalities cannot recoup costs of services needed because of a citizen's negligence absent a statute (Krauss, 2006; Lytton, 2002). The most compelling rationale for this controversial doctrine is that part of government's role is to provide services to the public financed via taxation that spreads the costs to all citizens (Lytton, 2002). Deciding how to allocate the costs of providing services should be left to the democratically elected legislature, as a matter of public policy, not to the courts (32 A.L.R. 6th 261; Krauss, 2006). We are unsure if this doctrine bars recovery in this instance; however, we believe that there is a case for allowing the courts to recoup these costs under a public nuisance doctrine, by analogy, especially since many states and municipalities have public nuisance statutes that can provide the statutory basis the Free Public Services Doctrine requires. See, for example, Cincinnati v. Beretta U.S.A. Corp., 768 N.E.2d 1136 (Ohio 2002) (holding that a city's allegation that the negligent conduct of the handgun manufacturers, trade associations, and handgun distributor, relating to the manufacture and distribution of firearms, involved continuing misconduct and stated a claim for recoupment of costs of government services, such as 
police, emergency, health, corrections, and prosecution services under a public nuisance theory); A lead paint case awarding damage on a series of public nuisance (California v. Atl. Richfield Co., 2014 WL 280526 (Cal.Super.)).

But handling the problem via a statutory scheme of some kind has substantial advantages. For example, it would allow the polity to decide, via the democratic process, on the terms for imposing such liability and the process for handling it. In addition, it would offer the opportunity to create a more streamlined and efficient administrative process rather than requiring an adversarial one. For those reasons, we propose a statute that will create a mechanism for recouping the costs of outbreak caused by nonvaccinating.

\section{Potential Models: Existing Statutes Imposing Costs}

Statutes imposing costs of public services on citizens exist in a variety of contexts (see Table 2). Several states have statutes allowing the state to recoup the costs of environmental hazards. For example, agencies may recoup the costs of handling fires (Wash. Rev. Code Ann. § 76.04.495 (West 2014); Cal. Health \& Saf. Code $§ 13009$ et seq. (West 2014); N.C. Gen. Stat. Ann. § 106-947 (West 2014)) or hazardous spills (Nev. Rev. Stat. Ann. § 459.537 (2), (3) (West 2014); Alaska Stat. Ann. § 46.03 .822 (West 2014); N.C. Gen. Stat. Ann. § 166A-27 (West 2014)). States and municipalities also have statutes allowing recovery in damages for nuisance. Nuisance can be defined broadly for example, California law defines it as "Anything which is injurious to health, including, but not limited to, the illegal sale of controlled substances, or is indecent or offensive to the senses, or an obstruction to the free use of property, so as to interfere 
with the comfortable enjoyment of life or property, or unlawfully obstructs the free passage or use, in the customary manner, of any navigable lake, or river, bay, stream, canal, or basin, or any public park, square, street, or highway, is a nuisance." (Cal. Civ. Code $\S 3479$ (West 2014)). Most examples relate to inadequate property management that causes harm to others (see, e.g. Sacramento City Code 8.04 .100 available at: http:/qcode.us/codes/sacramento/) though the principle can be seen as broad enough to encompass non-vaccination. While that is not the focus of this article, it is certainly a possibility.

In addition to requiring property owners and others causing environmental hazards to internalize the costs of their choices, these laws also reflect a value judgment. In particular, they support the idea that the public should not have to pay for the costs of those behaviors. They can also help deter such problematic behavior by imposing costs on the actors. This the same logic we wish to apply to non-vaccination.

Finally, a small number of states have statutes addressing recovery of costs spent on rescuing an individual from a dangerous situation created by the individual's own negligence. For example, the Arizona Stupid Motorist Act (Ariz. Rev. Stat. Ann. § 28910 (West 2014)) allows non-profit and public entities to collect costs expended in rescuing a driver who, ignoring barricades (or otherwise behaving recklessly), drives a vehicle onto a public street or highway that is temporarily covered by floodwaters. Similarly, North Carolina has a statute that allows government agencies to recover costs incurred in rescuing someone during an emergency if the person rescued ignored a warning (N.C. Gen. Stat. Ann. § 166A-19.62 (West 2014)). The logic behind these 
statutes is that if the need for public assistance was brought about by an individual's highly culpable behavior, then the individual should reimburse the public purse.

Drawing on these existing models, we propose a statute that imposes the costs on those whose choice to note vaccinate caused them. The statute follows the logic embodied in existing recovery statutes, and draws heavily on the Arizona statute for its specifics.

\section{Bill Text:}

Title of Bill: Recovering Costs of Outbreaks Caused by Non-Vaccinating

SECTION 1: A person whose decision not to vaccinate herself or a minor under her control caused or contributed to an outbreak of an infectious disease is liable for the costs incurred by public agencies in containing and treating the disease if:

(a) Vaccination of said individual and/or minor against the disease is recommended by the Advisory Committee on Immunization Practices (ACIP).

(b) The individual chose to forgo said vaccination for non-medical reasons.

(c) Vaccination of the individual and minor would, more likely than not, have prevented the outbreak.

In considering which costs, if any, to impose on that individual, the agency will consider:

1. How contagious the disease is.

2. The rate of complications imposing long-term costs from the disease.

3. The difficulty of investigating the disease.

4. Other equities, such as objective difficulties in obtaining a vaccine or getting a child vaccinated.

SECTION 2: violation of section 1 is a public nuisance.

SECTION 3: The agency or agencies responsible for containing and managing the outbreak will determine that the requirements above are fulfilled, assess the costs of investigation, containment and treatment and provide the liable party with a reasoned decision and an itemized bill. Once provided, the charge constitutes a debt of that person and may be collected proportionately by the public agencies that incurred the expenses.

SECTION 4: An individual determined by the agency or agencies to be liable under Sections 1 and 2 may appeal the decision to impose costs, and such an appeal will be heard by a hearing officer in the billing agency or in the state's Department of Health (in the case of a private entity) 
according to the procedures enumerated in $\$ 556-557$ of the Administrative Procedures Act or the state equivalent. The agency's final decision may be appealed to the state's courts.

SECTION 5: The State Department of Health will have the authority to promulgate rules to implement this statute.

SECTION 6: Qualifying for a religious or personal belief exemption under state law is not a defense against liability.

SECTION 7: A notice of this potential liability will be provided to parents or patient at each doctor visit in which vaccines should be offered according to the CDC's immunization schedule and along with the form used to obtain an exemption from the state's immunization requirements.

\section{Discussion}

The statute makes not vaccinating a public nuisance and forcing individuals to internalize those costs. It thus fits comfortably within the ideas of personal responsibility embodied in our system: individuals are free (subject to other applicable rules, like school immunization requirements) not to vaccinate themselves or their children. If, however, an individual's choice creates risk, then the individual is required to pay for those risks if they materialize. The specific risk the statute enacts is the costs of outbreaks borne by those having to contain them. By using principles of nuisance, it justifies liability whether or not we view not vaccinating as negligent. By requiring causation, it keeps the principles of justice that justify compensation in other contexts.

The statute's remedy here is a public law remedy. That means that it needs to follow public law norms in substance and procedures. The decision must be based on the appropriate criteria. Procedurally, it must be reasoned and transparent. Once written and reasoned, allowing the entity seeking reimbursement to collect it as a debt - again, 
following the Arizona statute - makes the initial process of recouping costs more efficient and streamlined.

The statutes offer the individual a process to challenge the decision via, in the first instance, an appeal to the public agency. In contrast to the simple, streamlined initial billing, the appeal process includes full formal adjudicatory procedures as described in the Administrative Procedures Act (or the state equivalent - for the purposes of the statute, the Administrative Procedures serves as a model and source of procedures). This will provide the parties the right to bring witnesses and documents and rights of crossexamination, as far as feasible. By offering an adversarial process, the statute offers the non-vaccinating party ample opportunity to correct errors in the initial decision. But by making the first step administrative it assures that the decision will be heard by officials with expertise in administrative adjudications and prevents adding burden to the courts. Courts will judicially review the decision if there is further appeal, but will not have to undertake the initial fact-finding.

In section 5, the statute clarifies that the state's decision to allow unvaccinated children to attend school if they obtain an exemption does not relieve the parent making that problematic choice from having to bear the cost of that choice to the public.

Both fairness and deterrence support providing notice to the individual beforehand of the potential costs. While individuals are on constructive notice of the law - not knowing the law is not a defense - it would be more effective and fair to provide individuals with a direct warning, if possible. Of course, if an individual does not visit a doctor or apply for an exemption, it may be impossible to alert them, but if there is an opportunity, they should be put on notice. Section 6 enacts a requirement of notifying the 
individual in two circumstances: during a doctor visit where vaccines are discussed, and if an individual applies for an exemption.

\section{Conclusion}

Not vaccinating has direct costs: beyond a certain level, it can and does increase the incidence of preventable diseases. Outbreaks, in turn, lead to direct monetary costs that often cannot be anticipated in advance, both the costs of treating the disease and the costs of containing it. When those costs come out of the public purse, resources are diverted from other needs, and important public values can suffer. There is abundant data showing that modern vaccines are effective and safe, and their small risks are far outweighed by their tremendous benefits. From this perspective, it is appropriate to require those who choose not to vaccinate to internalize the costs of that choice, rather than imposing them on the public. There are several tools available to allow that. We should use them.

\section{Bibliography}

Clandrillo SP. Vanishing Vaccinations: Why Are So Many Americans Opting Out of Vaccinating Their Children? U. Mich. J.L. Reform. 2004; 37:353.

Fine P, et al. Herd Immunity: A Rough Guide. 52 Vaccines. 2011; 52:911.

Kennedy AM, Brown CJ, and Gust DA. Vaccine Beliefs of Parents Who Oppose Compulsory Vaccination. Public Health Reports. 2005; 120(3): 252-258.

Krauss MI. Public Services Meet Private Law. San Diego L. Rev. 2005; 44:1. http://www.law.gmu.edu/assets/files/publications/working_papers/06-33.pdf.

Lobel, O. and Amir, O. Healthy Choices: Regulatory Design and Processing Modes of Health Decisions (July 1, 2011). Available at SSRN: http://ssrn.com/abstract=1876734 or http://dx.doi.org/10.2139/ssrn.1876734 
Lytton T, Should Government Be Allowed to Recover the Costs of Public Services from Tortfeasors?: Tort Subsidies, the Limits of Loss Spreading, and the Free Public Services Doctrine. Tul. L. Rev. 2002; 76:727.

Offit PA. Deadly Choices: How the Anti-Vaccine Movement Threatens Us All. New York: Basic Books, 2010.

Online Symposium: Liability for Exercising Personal Belief Exemptions from Vaccination. Mich. L. Rev. First Impressions. 2009;107:90-119. (application of tort law to failure to vaccinate)

Diekema DS. Commentary, Choices Should Have Consequences: Failure to Vaccinate, Harm to Others, and Civil Liability, Mich. L. Rev. First Impressions. 2009; 107:90.

http://www.michiganlawreview.org/firstimpressions/vol107/diekema.pdf.

Gordon J. Commentary, Parents Should Not Be Legally Liable for Refusing to Vaccinate Their Children, Mich. L. Rev. First Impressions. 2009; 107:95. http://www.michiganlawreview.org/firstimpressions/vol107/gordon.pdf.

Rubin DB \& Kasimow S. Comment, The Problem of Vaccination Noncompliance: Public Health Goals and the Limitations of Tort Law. Mich. L. Rev. First Impressions. 2009; 107:114. http://www.michiganlawreview.org/firstimpressions/vol107/rubinkasimow.pdf.

Schwartz JL. Commentary, Unintended Consequences: The Primacy of Public Trust in Vaccination, Mich. L. Rev. First Impressions. 2009; 107:100. http://www.michiganlawreview.org/firstimpressions/vol107/schwartz.pdf.

Stewart AM. Commentary, Challenging Personal Belief Immunization Exceptions: Considering Legal Responses. Mich. L. Rev. First Impressions. 2009; 107:105. http://www.michiganlawreview.org/firstimpressions/stewart.pdf.

Teret SP \& Vernick JS. Commentary, Gambling with the Health of Others. Mich. L. Rev. First Impressions. 2009; 107:110. http:// www.michiganlawreview.org/firstimpressions/vol107/teretvernick.pdf.

Parkins C. Protecting the Herd: A Public Health, Economics and Legal Argument for Taxing Parents Who Opt-Out of Mandatory Childhood Vaccinations. S. Cal. Interdisc. L.J. 2012; 21:437-490. 
Yang YT and Debold V. A Longitudinal Analysis of Nonmedical Exemption Law and Vaccine Uptake on Vaccine-Targeted Disease Rates. Am. J. Pub. Health. 2014; 104:371.

\section{Legal Authority}

\section{Federal Statutes}

Patient Protection and Affordable Care Act (ACA), 111 P.L. 148, 124 Stat. 119, 2010

Enacted H.R. 3590, 111 Enacted H.R. 3590 (2010).

\section{Federal Case Law}

Nat'l Fed'n of Indep. Bus. v. Sebelius, 567 U.S.__ (2012), 132 S.Ct 2566 (2012).

Employment Div. v. Smith, 494 U.S. 872 (1990).

Zucht v. King, 260 U.S. 174 (1922).

Jacobson v. Massachusetts, 197 U.S. 11 (1905).

Pennsylvania v. Gen. Pub. Utils. Corp., 710 F.2d 117 (3d Cir. 1983).

\section{State Statutes}

Alaska Stat. Ann. § 46.03.822 (West 2014).

Ariz. Rev. Stat. Ann. § 28-910 (West 2014).

Cal. Civ. Code $\S 3479$ (West 2014).

Cal. Health \& Saf. Code $§ 13009$ et seq. (West 2014).

N.C. Gen. Stat. Ann. § 106-947 (West 2014).

N.C. Gen. Stat. Ann. § 166A-19.62 (West 2014).

N.C. Gen. Stat. Ann. § 166A-27 (West 2014).

Nev. Rev. Stat. Ann. § 459.537 (West 2014).

Wash. Rev. Code Ann. § 76.04.495 (West 2014).

\section{State Case Law}


Commonwealth v. Twitchell, 617 N.E.2d 609 (Mass. 1993).

Shorter v. Drury, 695 P.2d 116 (Wash. 1985), cert. denied Shorter v. Drury, 474 U.S. 827 (1985).

State v. Norman, 808 P.2d 1159 (Wash. App. 1991).

Reed v. Tacoma Ry. \& Power Comp., 188 P. 409 (Wash. 1921).

\section{International Caselaw}

Vaughan v. Menlove, 132 Eng. Rep. 490 (C.P.) (1837) 
Moser, Reiss, Schwartz Funding Costs; Draft, do not cite or quote without permission of authors 3 June 2014

\section{Appendix A: Table 1: Costs of Outbreaks}




\section{Appendix B: Table 2: Statutes Addressing Cost Recovery}

\begin{tabular}{|c|c|c|c|}
\hline Goal: & \multicolumn{3}{|c|}{$\begin{array}{l}\text { Agency recovery for costs incurred during response to vaccine } \\
\text { preventable disease outbreaks. }\end{array}$} \\
\hline Issue: & \multicolumn{3}{|c|}{$\begin{array}{l}\text { Public cost recovery for action is generally barred the Municipal Cost } \\
\text { Recovery Rule or Free Public Services Doctrine. } \\
\text { In general, courts do not allow state, municipal, or government agencies } \\
\text { to recover in common law for costs expended carrying out public services } \\
\text { from the tort-feasors whose negligent conduct caused the need for those } \\
\text { services. The common-law rule by which the courts are guided in these } \\
\text { instances is the "municipal cost recovery rule" (county, state, or } \\
\text { municipality) or "free public services doctrine" (government agency). } \\
\text { The doctrines (which are used interchangeably by the courts) provide that, } \\
\text { "absent specific statutory authorization or damage to government-owned } \\
\text { property, a government agency, county, state or municipality cannot } \\
\text { recover the costs of carrying out public services from a tort-feasor whose } \\
\text { conduct caused the need for the services." ( } 32 \text { A.L.R. 6th 261.) } \\
\text { The primary rationale behind the free public services doctrine is that, } \\
\text { absent specific statutory authorization, state legislatures establish local } \\
\text { governments to provide core services for the public and pay for these } \\
\text { services by spreading the costs to all citizens through taxation. That the } \\
\text { question of whether the costs of providing the public service should be } \\
\text { spread among all taxpayers, or reallocated in some other manner, } \\
\text { necessarily implicates fiscal policy, and, therefore, falls within the special } \\
\text { purview of the legislature, not the court. ( } 32 \text { A.L.R. 6th 261.) } \\
\text { Other suggested rationales are that tortfeasors owe government entities no } \\
\text { duty of care that would support recovery, and that the doctrine suggests } \\
\text { thats should avoid upsetting settled expectations. }\end{array}$} \\
\hline $\begin{array}{l}\text { Means of } \\
\text { overcoming } \\
\text { a } \\
\text { presumptio } \\
\text { n of Free } \\
\text { Public } \\
\text { Services: }\end{array}$ & $\begin{array}{l}\text { Emergency } \\
\text { Response } \\
\text { Recovery } \\
\text { Statutes, } \\
\text { e.g. }\end{array}$ & Pubic Nuisance Ordinances & $\begin{array}{l}\text { Model } \\
\text { State } \\
\text { Emergenc } \\
\text { y Health } \\
\text { Powers } \\
\text { Act }\end{array}$ \\
\hline $\begin{array}{l}\text { Recovery } \\
\text { Sources: }\end{array}$ & $\begin{array}{l}\text { Forest Fires: } \\
\text { See e.g., } \\
\text { Cal. Health }\end{array}$ & $\begin{array}{l}\text { Common law doctrine, qualified by statute } \\
\text { and ordinances: } \\
\text { see e.g., }\end{array}$ & \begin{tabular}{|l|} 
MODEL \\
STATE \\
EMERGEN \\
CY \\
HEALTH
\end{tabular} \\
\hline
\end{tabular}




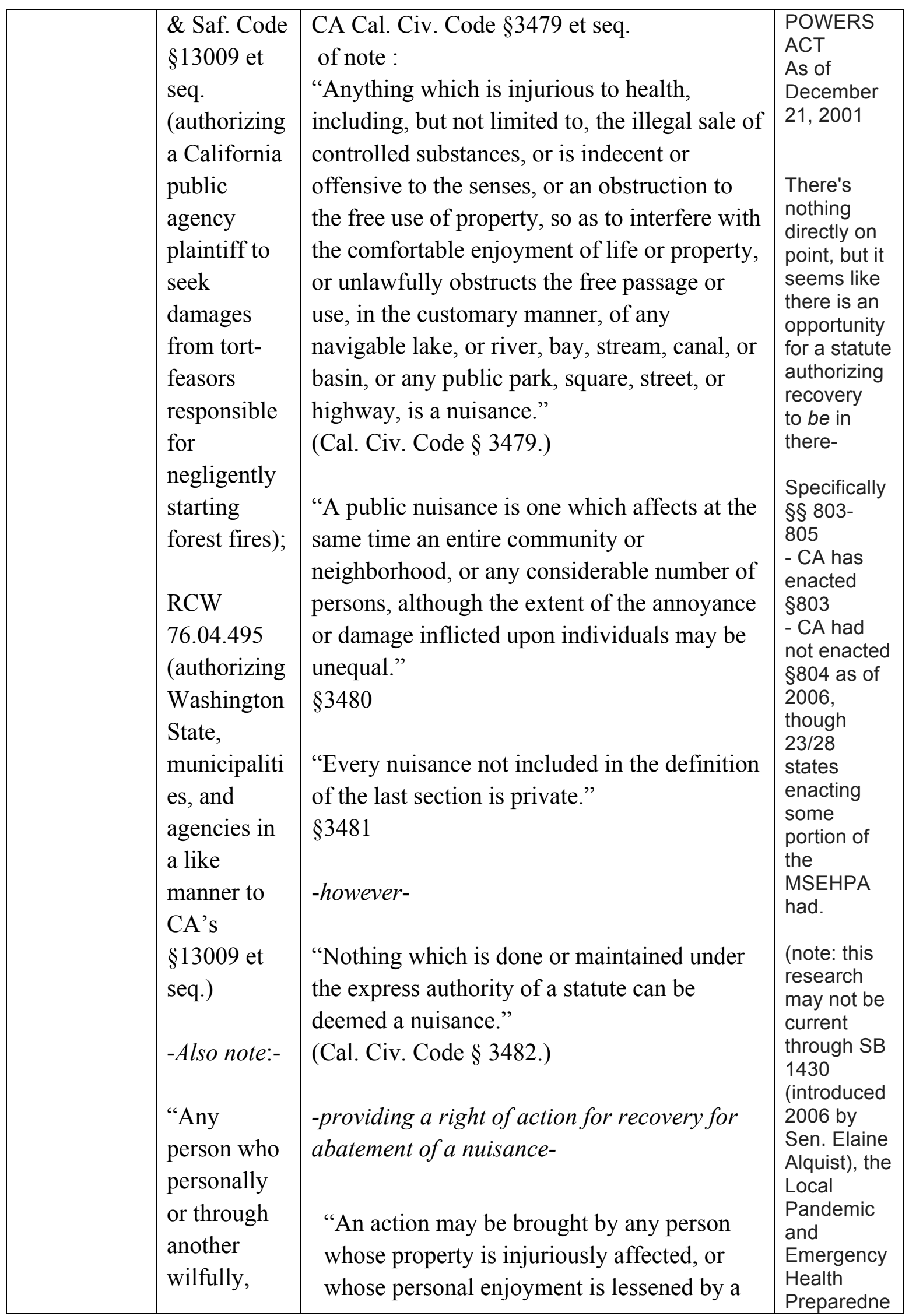




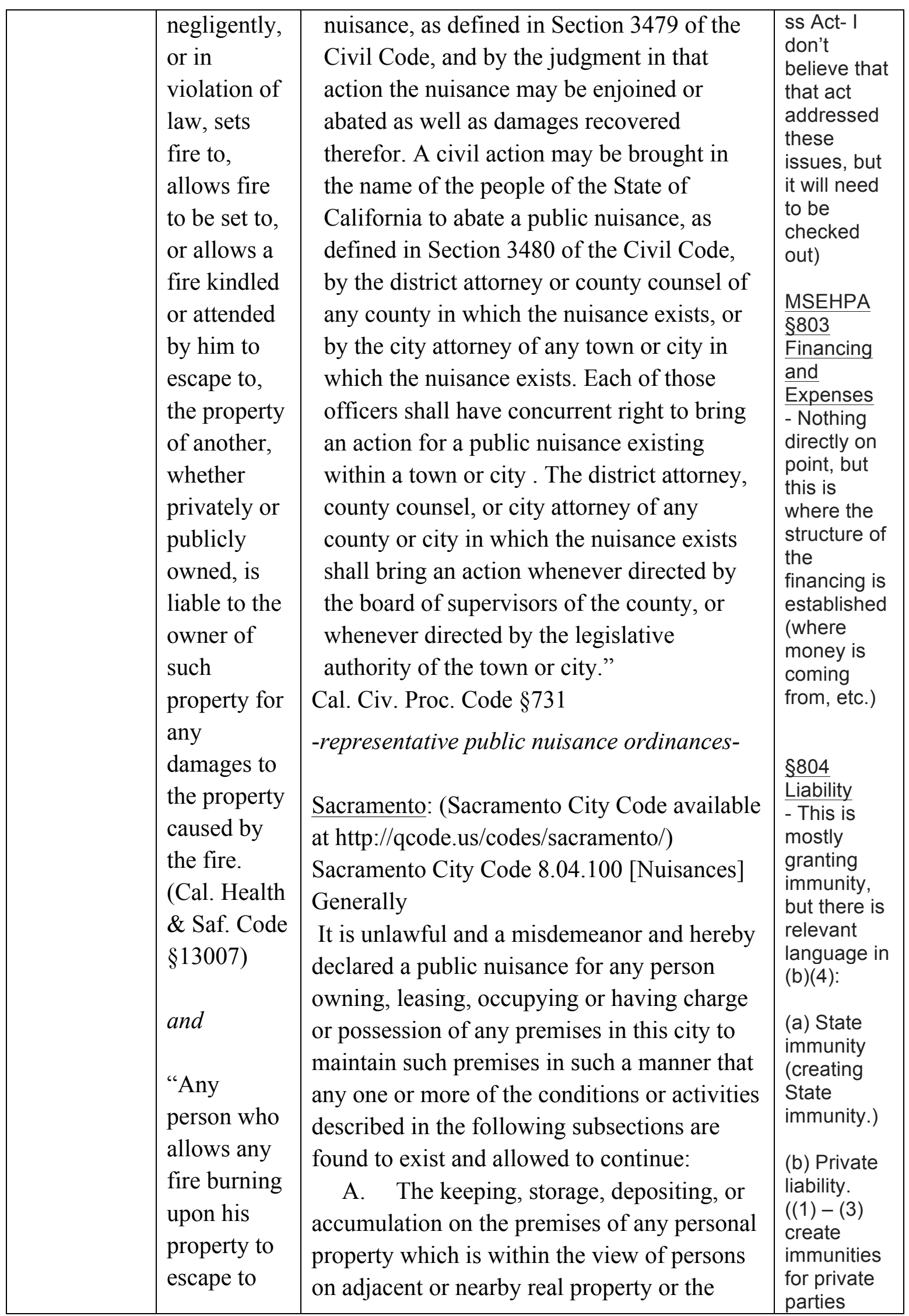




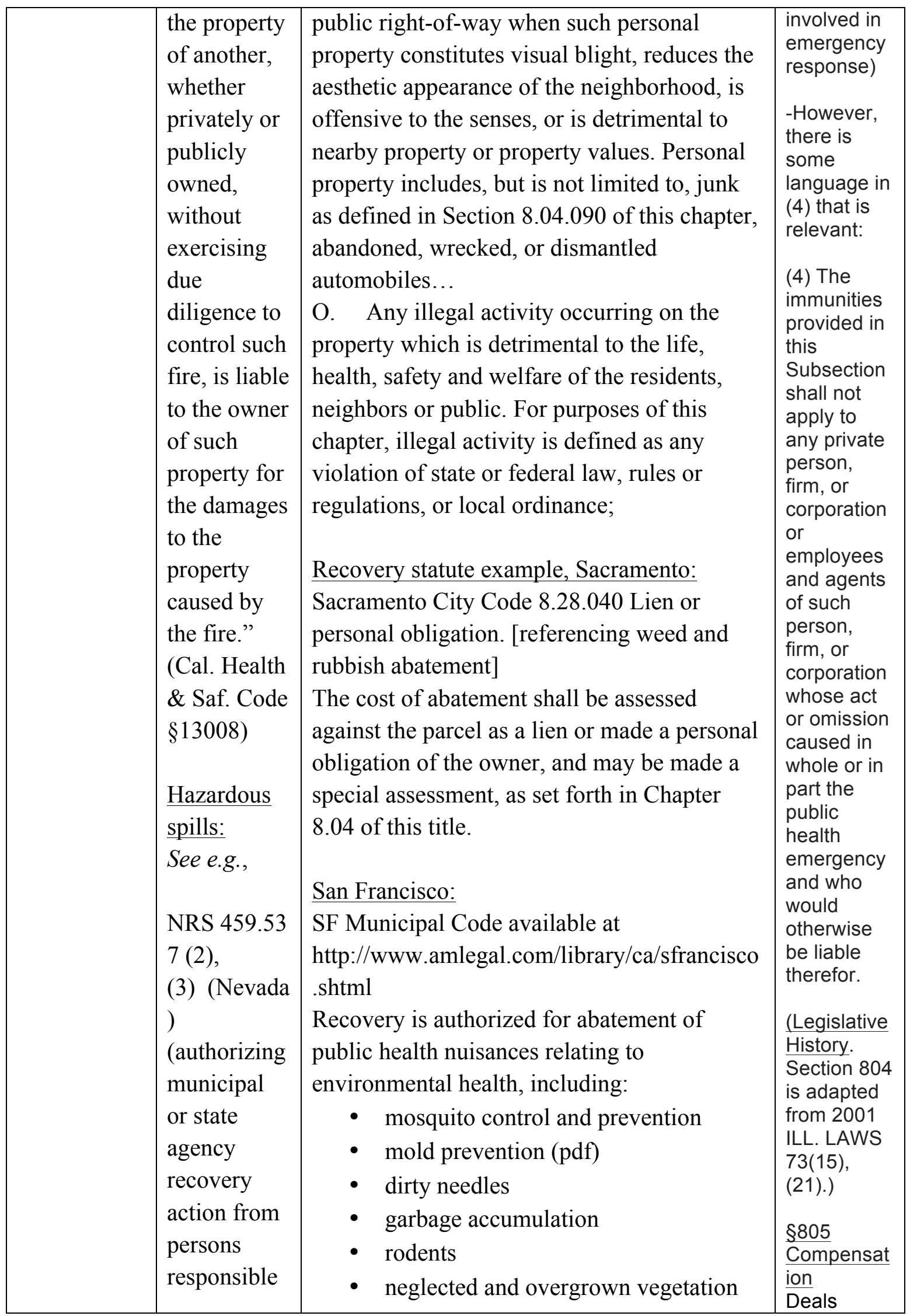




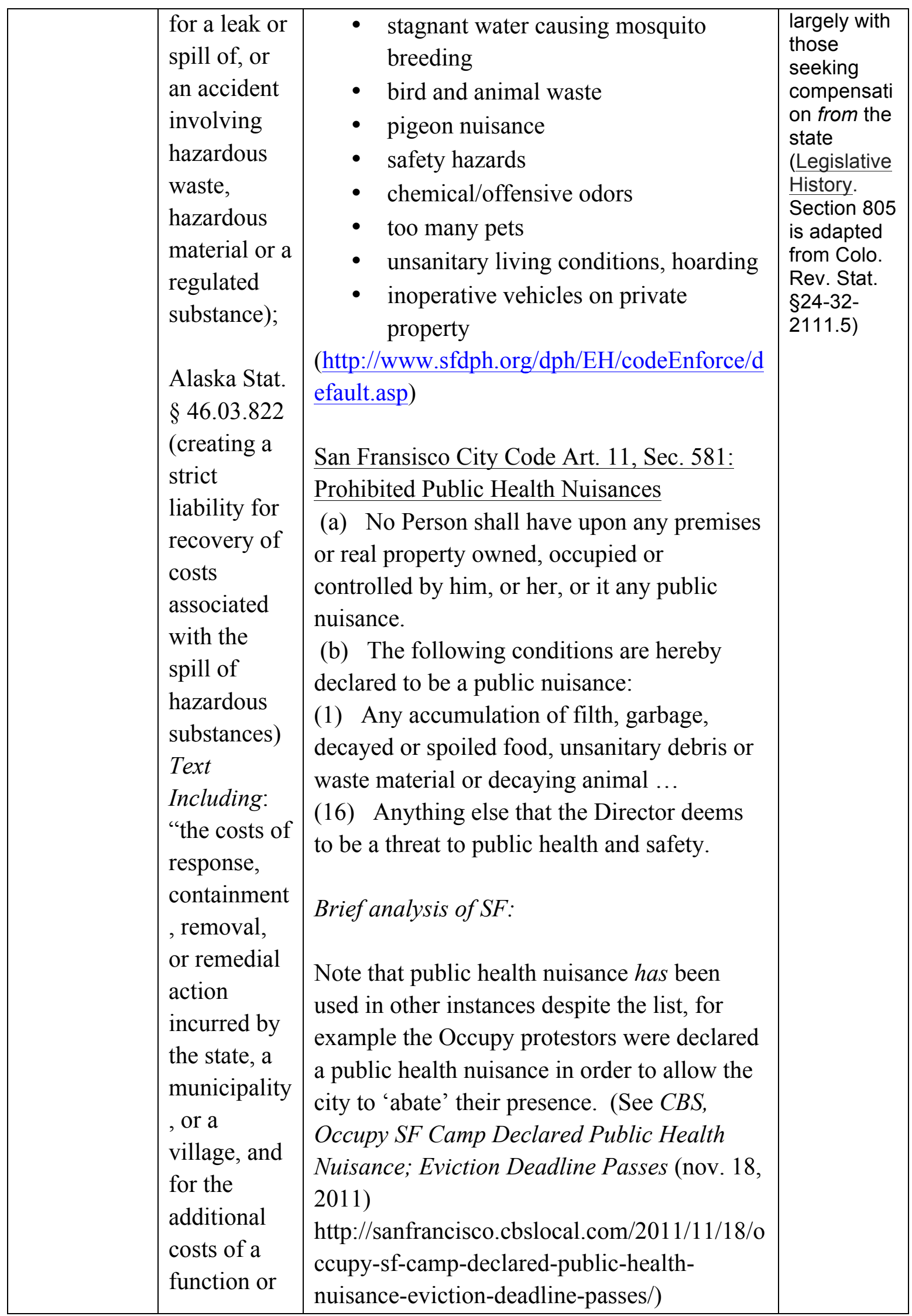




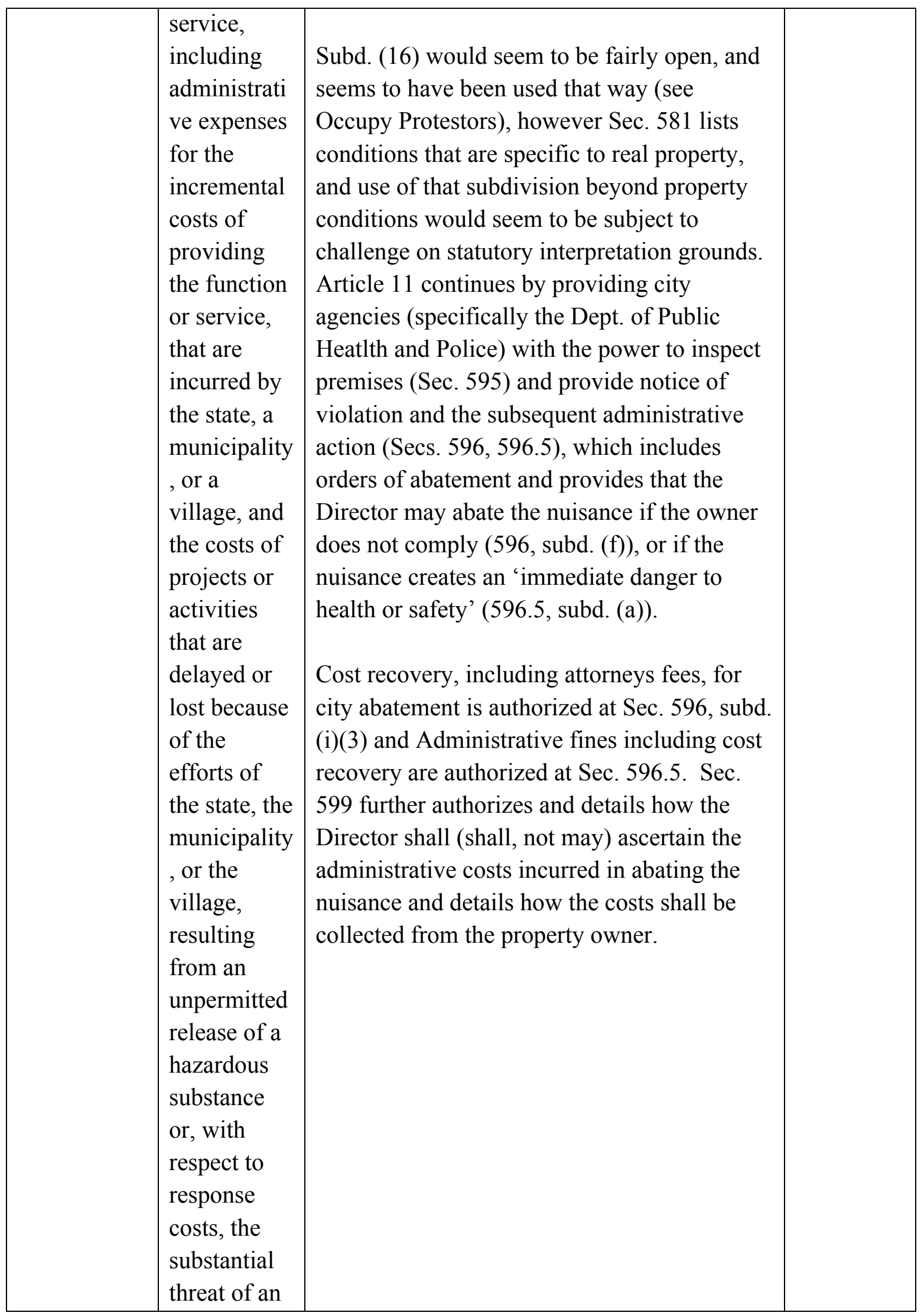




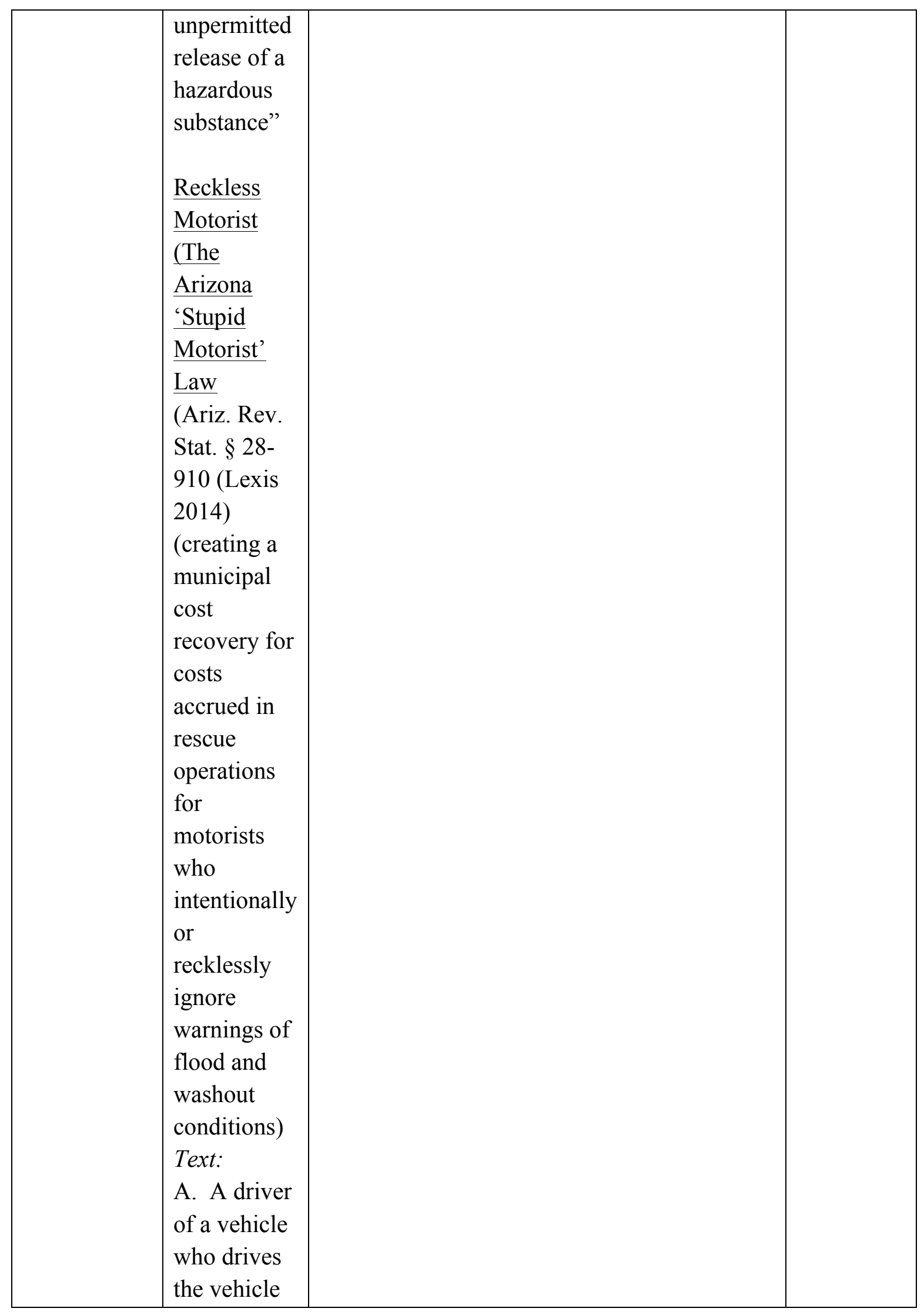




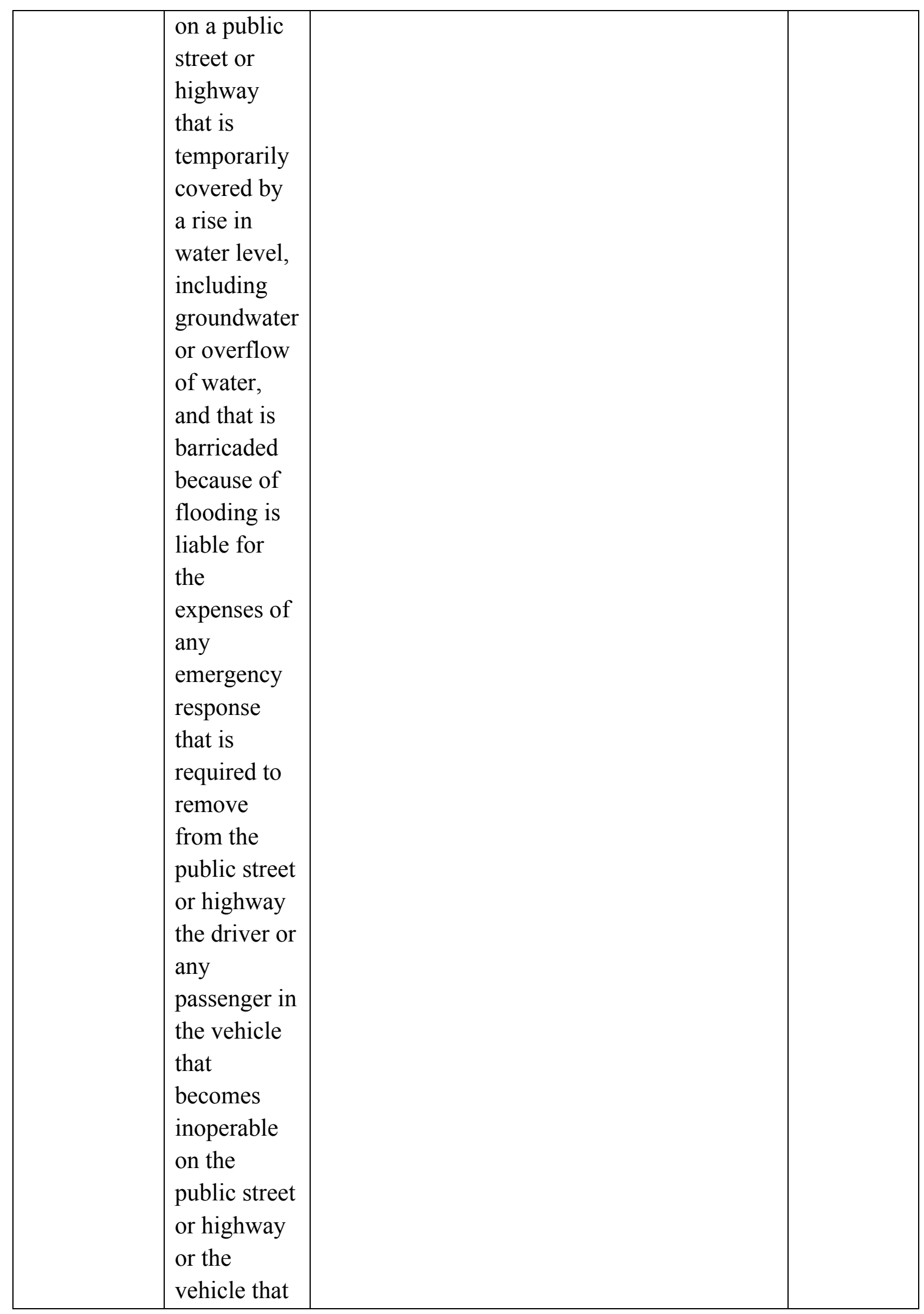




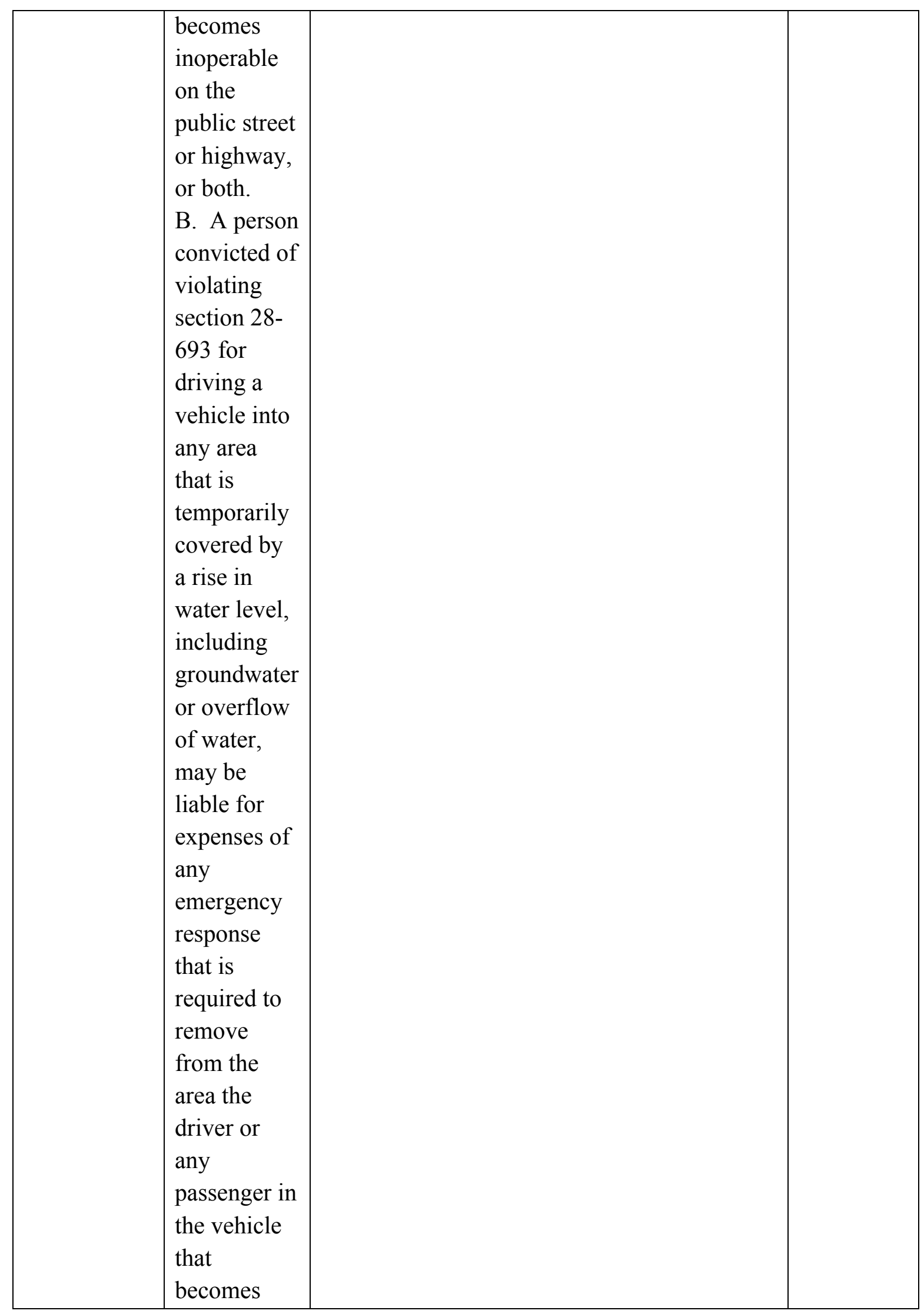




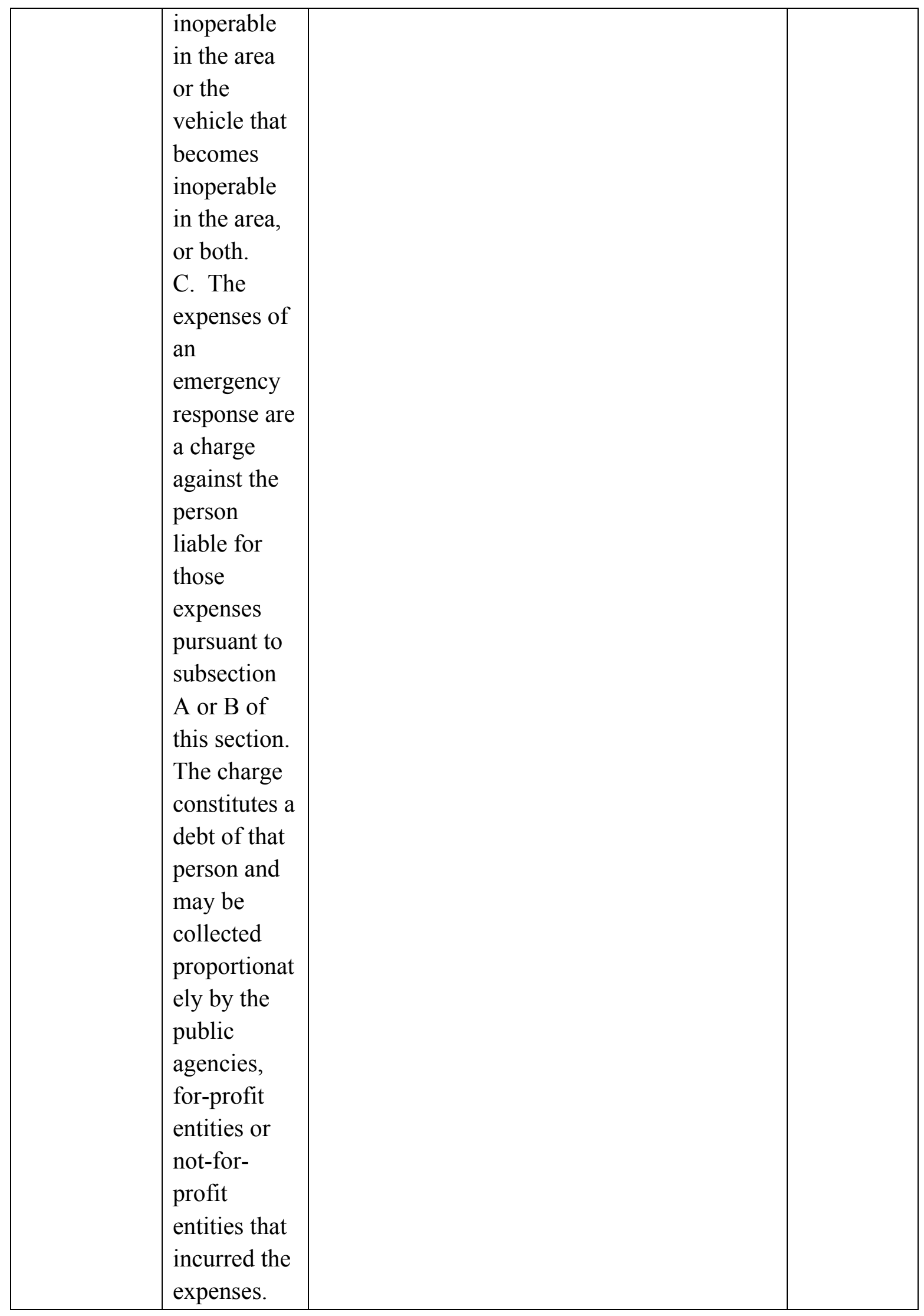




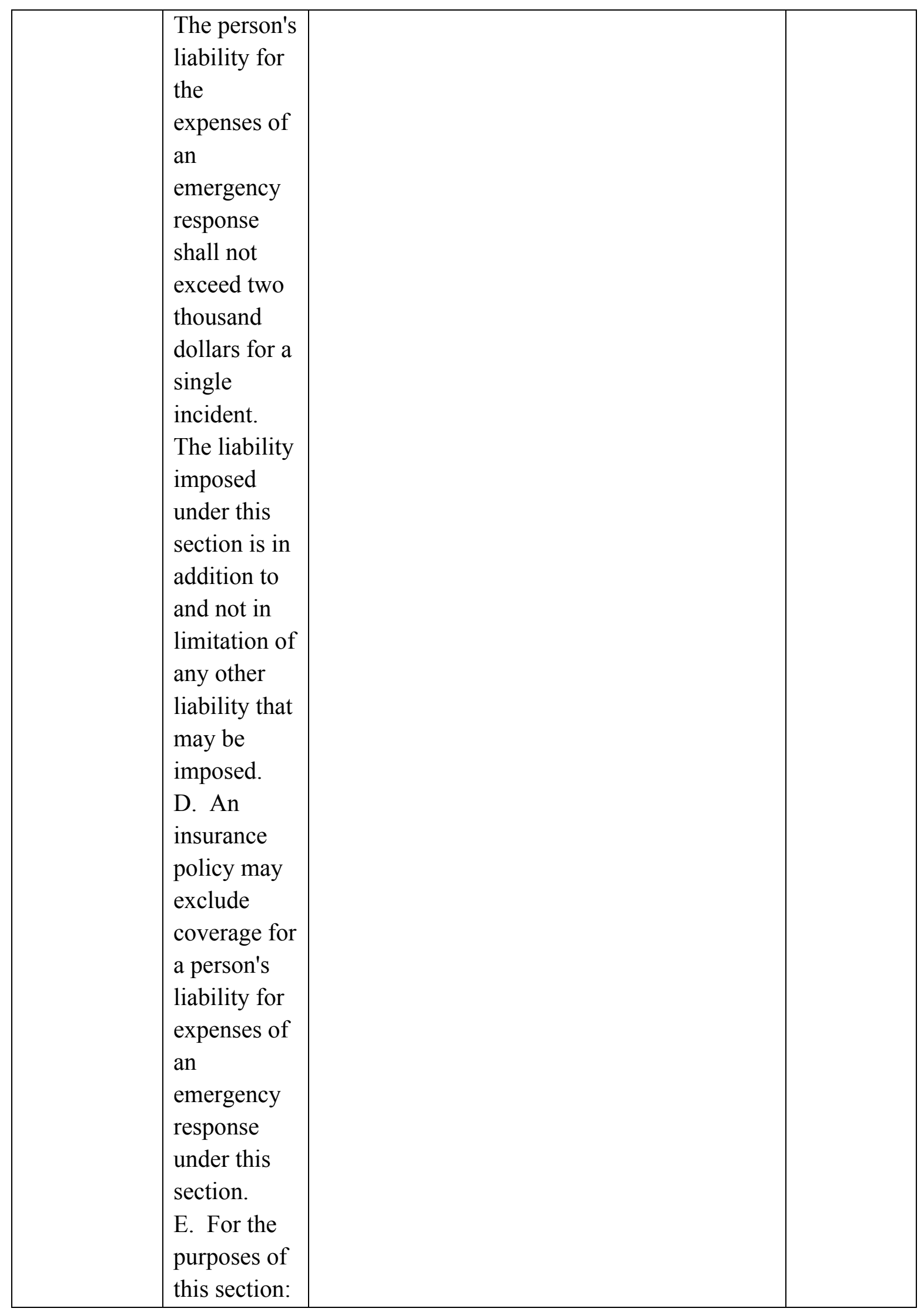




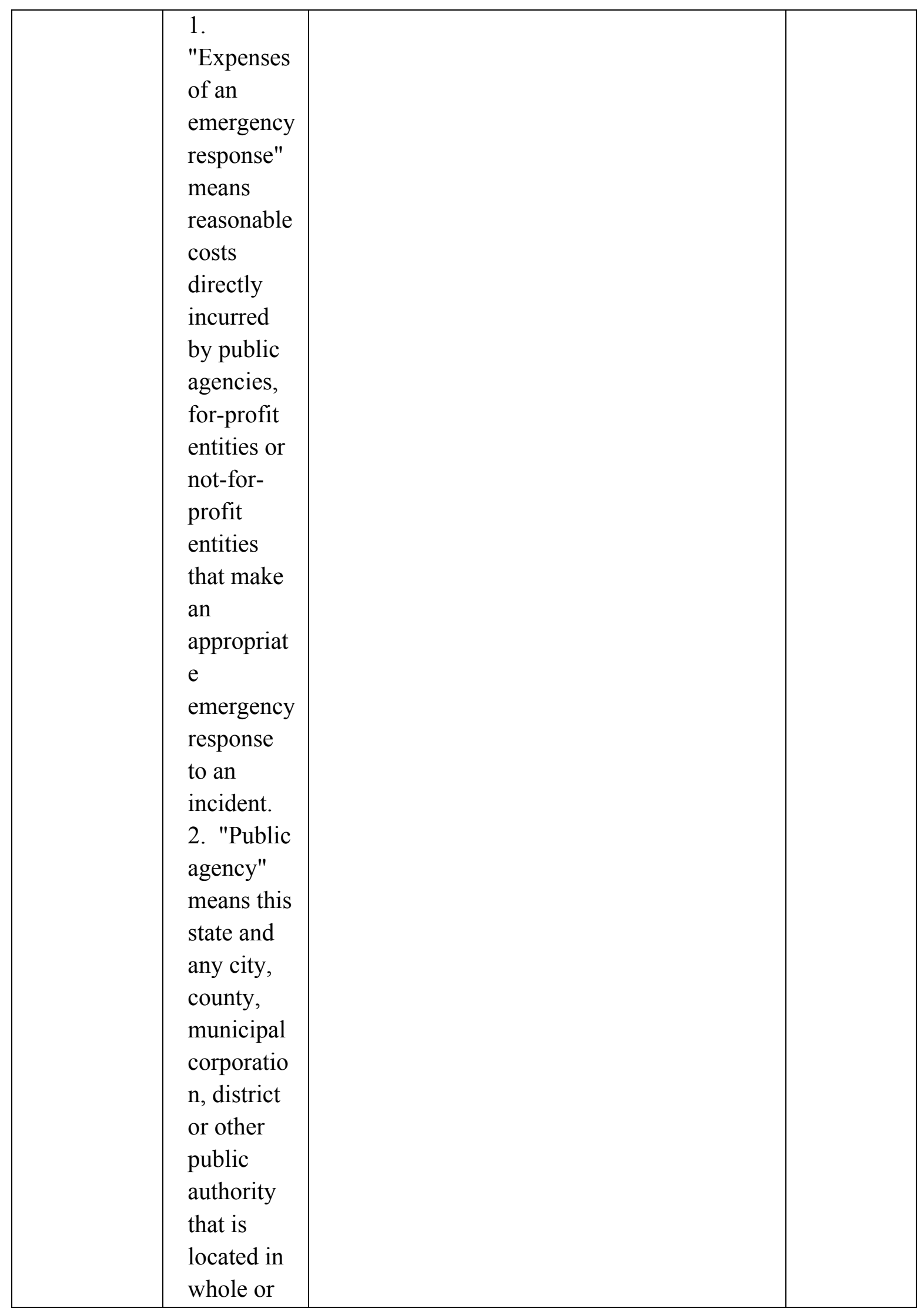




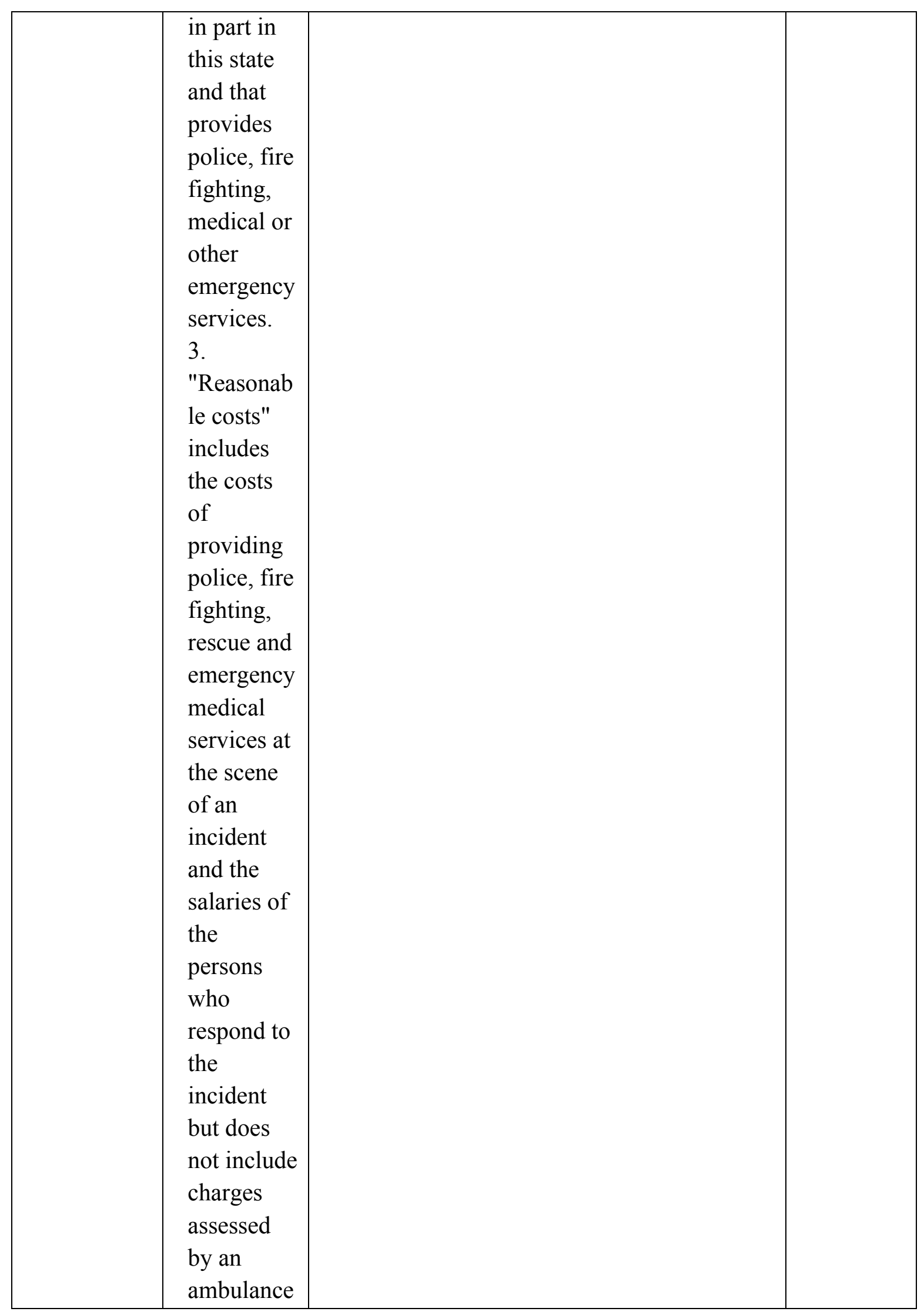




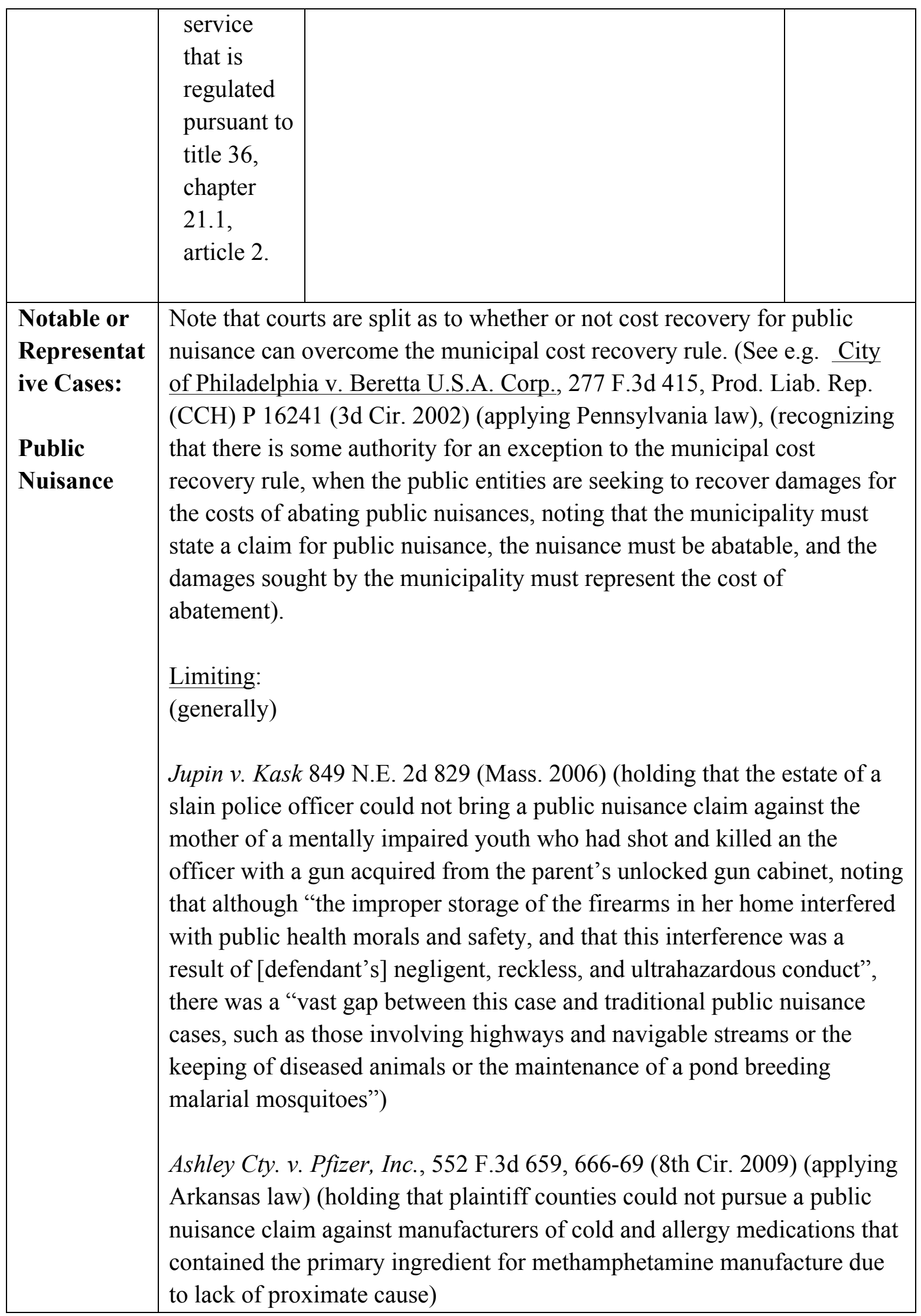


Walker County v. Tri-State Crematory, 643 S.E.2d 324, 328-29 (cert. denied) (Georgia App. 2007) (holding that, where county brought a negligence and public nuisance action against owners and operators of a crematorium, and the county sought to recover the expenses it incurred in recovering, identifying, and properly disposing of bodies found at the crematorium, that where there was statutory authority providing lien and recovery of expenses from property owners, the county was barred from using public nuisance to bring an action for recovery in tort) (further holding that there is no exception to the free public services doctrine when the costs are incurred as part of the abatement of a public nuisance since if such an exception were recognized, it could give rise to substantial litigation because litigants could re-characterize many expenditures for public services as expenses incurred in abating a public nuisance)

(lead paint)

State v. Lead Indus. Ass'n, Inc., 951 A.2d 428, 443 (R.I. 2008) (holding that the manufacture and use of lead paint was not a public nuisance because it had not 'interfered with a public right.')

(guns)

City of Chicago v. Beretta U.S.A. Corp., 821 N.E.2d 1099 (Ill. 2004), (holding that the municipal cost recovery rule precluded a city and a county, in a public nuisance action against firearms manufacturers, distributors, and dealers, from recovering for law enforcement and medical services expenditures allegedly incurred as a result of gun violence)

-but see-

Cincinnati v. Beretta U.S.A. Corp., 768 N.E.2d 1136 (Ohio 2002) (holding that a city's allegation that the negligent conduct of the handgun manufacturers, trade associations, and handgun distributor, relating to the manufacture and distribution of firearms, involved continuing misconduct and stated a claim for recoupment of costs of government services, such as police, emergency, health, corrections, and prosecution services under a public nuisance theory);

See also, City of Gary ex rel. King v. Smith \& Wesson Corp., 801 N.E.2d 1222 (Ind. 2003);

James v. Arms Technology, Inc., 820 A.2d 27 (N.J. 2003) 


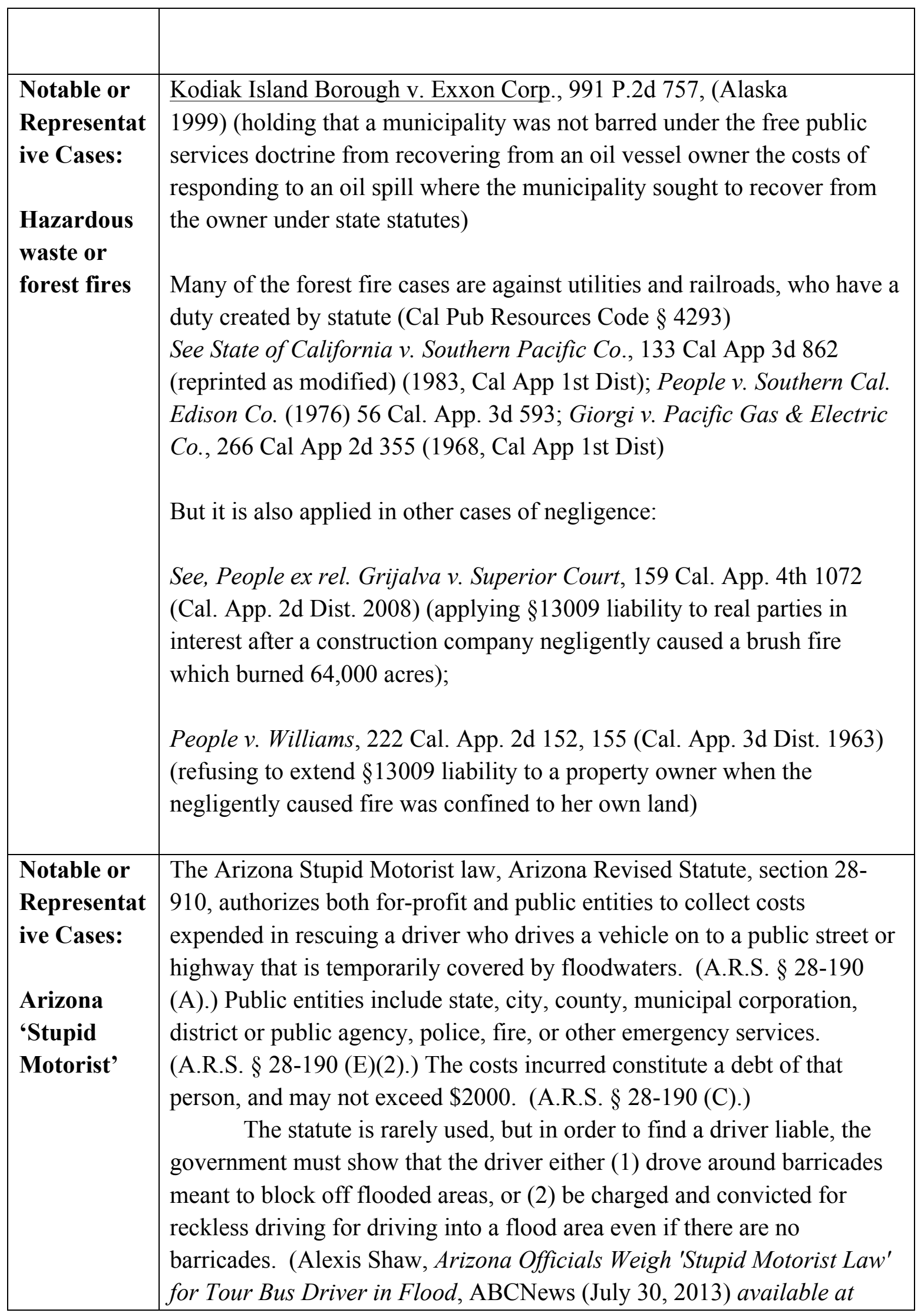


Moser, Reiss, Schwartz Funding Costs; Draft, do not cite or quote without permission of authors 3 June 2014

\begin{tabular}{|l|l|}
\hline & $\begin{array}{l}\text { http://abcnews.go.com/US/arizona-officials-weigh-stupid-motorist-law- } \\
\text { tour-bus/story?id=19817085 (quoting Chief Deputy Mojave County } \\
\text { Attorney Jace Zack).) }\end{array}$ \\
\hline
\end{tabular}

